\title{
Multicriteria Decision Integrated Prospective Theory Applied at Engineering Services' Company
}

\author{
José Artur Vieira, Marcela do Carmo Silva, Carlos Francisco Simões Gomes*, Marcos dos Santos
}

Federal Fluminense University, Rua Passos da Pátria, 156 - Bloco D - room 309, São Domingos, Niterói, Brazil

Copyright $\mathrm{O} 2018$ by authors, all rights reserved. Authors agree that this article remains permanently open access under the terms of the Creative Commons Attribution License 4.0 International License

\begin{abstract}
This paper proposes a model integrates future scenario planning techniques, based on the Multicriteria Decision Aid (MCDA) approach, which can be used as a tool for attending companies' strategic planning, applying it to an engineering company services, located in the State of Rio de Janeiro, Brazil. The motivation of the studied theme is the possibility of applying MCDA techniques added to the future scenario concepts planning as a tool for strategic (and progress) planning. Thus, the usefulness of the proposed model was proven, since it enabled the manager to analyse investment alternatives in the light of the future prospecting conducted. Recent discussions suggest the use of resources in an optimized way due to the increasing scarcity. This fact makes decision-making and strategic planning based on future scenarios a complex task, since it has multiple and uncertain alternatives. A bibliographic review was performed to identify methods are more applicable to the problems. An innovative proposal is made to unite prospective with multicriteria in a compensatory problem; proposing a methodology with six steps.
\end{abstract}

Keywords Business, MCDA, Future Scenario's Prospection, Management, Engineering Service's Company

\section{Introduction}

The world economy was structurally modified between the end of the 19th and the middle of the 20th centuries; "the capitalist model was consolidated and later evolved, gaining modern features and founding the society of mass consumption. The evolution of society in all aspects resulted in a great change in the market, leaving it dynamic in its commercial form, allowing the emergence of new opportunities and segments.

These cultural and technological evolutions have brought with it the evolution of other factors, such as social, environmental, economic etc.; generating, therefore, a strong demand for tools of aid to the decision makers. Per Porter [53], to realize an effective mapping of the external environment is of paramount importance for organization to remain competitive.

The external environment increasingly affects the emergence and development of organizations that seek to enter new markets or remain present. The socio-cultural and economic factors have a direct influence on the development or emergence of organizations in new sectors, showing the importance of them from a business perspective. Daychouw [21], the organizations need to understand all the factors capable of influencing them to be successful in their useful lives. Such understanding evidences the complexity in the definition of strategies that guarantee the survival of the organizations in this competitive environment.

Thus, a key tool for the strategic planning process is the prospection of future scenarios, since it considers multiple and uncertain alternatives. When the manager starts to plan using scenarios, this organization takes a step forward in its management and decision-making maturity, since they are considered different scenarios futures; which results in more agile responses and relative reduction of complexity relationship between organizations versus positioning in the future [3]. Scenario exploration is an optimized way of thinking about a wide variety of potential variables that may impact the future of an organization. Fouquet [32] sought to investigate the known challenges related to Life Cycle Assessment (LCA) buildings. Dynamic LCA enables a more consistent analysis of the emission flows and impacts of global warming over time. Prospective LCA can provide more relevant LCA results, but increases uncertainty and could be used as a sensitivity analysis.

Millan et al [51] affirm that in a globalized business environment, where variables such as technology, environment, human and physical resources are associated with competitiveness, in this context, tools that help in this task gain importance. The authors also affirm that the use of management models by companies, regardless of the 
area to which they belong to; they guide these companies to the improvement of its productivity and profitability.

In the light of the foregoing, the following question arises: the elaboration of a model that can be used as a tool to support the manager in his decision-making, regarding the strategic planning of the organization, would be adequate to reduce intrinsic risks to the activity of planning in complex environments?

Scenario-based foresight techniques are often used in futures studies to deal with the challenges posed by complexity and uncertainty. Scenarios are developed in different ways. The two major categories of scenario construction approaches are intuitive (soft) methods that are based on qualitative knowledge and insight of experts or stakeholders, and formal (hard) methods that are based on best scientific knowledge and quantitative models [27].

Futures practitioners and researchers are often seen as divided into two groups: the positivist, 'probability' camp sees uncertainty as something that needs to be reduced to better assess the likelihood of future conditions.

On the other hand, the constructivist or 'plausibility' camp sees scenarios as a tool that is primarily useful in conditions when prediction is not deemed possible. Future scenarios are often considered plausible if they offer both internally consistent narratives and a logical development from present conditions. They point out that even constructivist plausibility approaches often bias imagined scenarios too much toward what is prominent in the present and observed in the past.

This paper aims to propose a model that integrates planning techniques for future scenarios, based on the Multicriteria Decision Aid (MCDA) approach, which can be used as a tool for assisting strategic planning of companies and applying it in an engineering services company, located in the State of Rio de Janeiro, Brazil.

This paper uses a multicriteria compensatory method (in according with company culture) to ordering alternatives in future scenarios.

The study comprises a descriptive and an exploratory research, proposing a tool to assist decision-makers/managers, in the strategic planning elaboration process based on the analysis of the various criteria that influence the organization. From the concepts, aforesaid, a theoretical-methodological model is proposed for structuring the study:

- Problem: evaluation of the alternatives at scenarios futures

- Theoretical Framework and Literature search: identify a strategic planning with future scenarios with a methodology to ordering alternatives

- Model proposal: identify a hybrid methodology to represent the company culture

- Model application: Application at company data.

- Evaluation results: discussion and suggests.

The first milestone for the model construction was the problem definition; thereafter it was thought what would be its theoretical basis. Next, a literature search was carried out related to the theoretical structure. The next step consisted in proposing the model followed by the application to a company and the evaluation of the results obtained.

\section{Materials and Methods}

It is undeniable that the economic globalization process originated in the 1990s, has altered the competitive market globally. This fact had in Brazilian industries the imperative of a full acceptance of the expectations and needs of the clients to survive in the "environment of intense competitiveness".

The strategic orientation of a firm reflects what set of actions it believes will lead to superior performance. Research indicates that a firm's strategic orientation as it emerges from experience, solutions and heuristics can result in path dependencies that influence organizational change and adaptability [56].

It should not be overlooked that there are significant differences in performance, which can be measured by financial results, sustainability indicators, production efficiency etc. between some companies and their competitors. There is also an enormous number of factors capable of influencing these differences, such as: activity area, local economy, location, management, among many other factors. The evolution of society in all aspects has had a great impact on the market, leaving it dynamic in its commercial form, allowing the emergence of new opportunities and segments.

The companies' performance can be explained considering two perspectives: the vision of the industry and the vision of the company. In the first, the industrial organization, the result is conditioned in terms of performance, efficiency and business opportunities. On the other hand, the reasons for higher performance are a function of their abilities, luck or commitment to a favourable competitive position [4]. That is, the industry view is related to the environment in which the company belongs to; and the second, and it is intrinsically related to the internal development of the same.

Dudley et al [24] describe an approach in which prospective scenarios are used, achieving a more rapid analysis of the effect of the new technique on the decision-making process. Durance \& Godet [26] tried to answer simple and important questions: What is a scenario? How to judge the quality of a scenario? What are the strategies for scenarios?

According to these authors, the applications of strategic prospecting tools are contingent and modular.

Lange [49] presents what is possible outside the method of prospective scenarios in general and compulsory education, searching through an empirical and case study approach, determine their viability, their contributions, limits, and locate the place of the scientific education in the 
elaboration of the perception of "vulnerability".

Considering firms as homogeneous, the industry itself could explain differences in competitive practices and, consequently, their results [33]. In this same direction, Porter [53] states that because of this more favourable environment, if a company's profits were higher than its competitors, in an extended period, that company would have a sustainable competitive advantage. The political, social, cultural and economic characteristics of the business environment of nations not only provide conditions for greater wealth and quality of life for their populations, but also better performance for their companies. In the last two decades of the twentieth century, strategic planning techniques from Porter's perspective became a dominant part of academic management models, especially in the United States of America. Another aspect is the Resource Based View, characterized by advantages obtained by greater operational efficiencies, resulting in the improvement of the companies' performance and extraordinary profits, obtained using its resources, not being preponderant the structure of the industry itself [4; 13].

It is evident that these aspects are not mismatched, that is, there is no way to affirm that the success or failure of a company is related to them, in isolation. It is noteworthy that the performance of companies varies not only per the industries to which they belong to, or their location, or their individual characteristics, but also per the more general environment in which they operate and in what way they do [64]. It is considered that "Every venture in its sociability fabric still sets up an intricate network of visibility strategies for the company, its brands and its products, and the consumer public".

From these perceptions that the set - external environment added to the internal - is capable of strongly influencing business performance, attention to techniques that help the management of companies and that encompasses such variables gains strength. The reasons for this growing attention to business strategy are many, and along with this is the creation of more sophisticated and complex control mechanisms. The growth of strategic planning stands out. The company can only grow and progress if it can adjust to the situation and strategic planning is a proven technique for such adjustments to be made with intelligence. Such instrument is more flexible than the so-called Long-term Planning, being a key element of the strategy, which forces or at least encourages managers to think in terms of what is important or relatively important and focusing on issues of relevance.

It should be clarified that this is not a question of Strategic Situational Planning (SSP), since it has characteristics that differentiate it from traditional planning methodologies. Highlight three:

i. It is planned based on problems and not from objectives;

ii. It is the subjective real-world approach, the perceptions and points of view of the individuals involved in the problematic situation under investigation, with the purpose of identifying and analysing it;

iii. Recognizes that the future is uncertain and it is not predicted. Therefore, it does not predict the future, but tries to create it from the possibilities that the individual who declares the problem can see.

The Strategy is concerned with the harmonization of resources, capabilities, competencies and objectives (mission and values) that allow a company to interpret opportunities and risk factors that may arise in the external environment [41].

The basic structure for the construction of a strategic vision contemplates the harmonization of resources, capacities, competencies and objectives (mission and values) that allow a company to interpret opportunities and risk factors that may arise in the external environment [41]. This structure is a link between the company and the environment in which it is located. It is worth noting that there are some shortcomings in the measurement and evaluation of its possible results, since these results depend on qualitative analysis [73], such insufficiencies could be set aside by quantitative approaches [75], as the model of this paper proposes, when it creates scales for qualitative analyses and makes tests of consistencies in the opinions of those involved, reducing the subjective in which this type of analysis is exposed.

\subsection{Future Scenarios}

To Schoemaker's [59] scenario planning is a structured (disciplined) methodology used to envision future possibilities. Scenario planning stands out for its ability to capture a wide range of possibilities and a large wealth of details.

Scenario development is a valuable tool to help organizations Scenarios considered a reference in future-building and scenario-planning studies [3]. The using of scenario planning, aids in $[3,38]$ :

- Identifying potential business opportunities;

- Testing a strategy in multiple scenarios [42];

- Monitoring the implementation of the strategy; reducing risks in decision making and increasing the probability of making the correct decision regarding these inevitable changes, it allows the company to be managed with more assertiveness in the maintenance of its business. [1]

- Researching changes in the environment to determine the strategies that should be adapted, and if necessary, alter the decisions for the survival of the businesses;

- Reducing the uncertainties regarding leadership's ability to promote adjustments;

- Promoting awareness and the generating of new 
opportunities; and,

- Increasing the quality of strategic thinking (reducing the practice of behaviour that is too routine, operational or bureaucratic).

- Clarify a chain of possibilities, or future events that can influence their decisions [22]; is a viewpoint that is based entirely on what the future could end up being, and with the forming of multiple scenarios, a company can systematically extrapolate the possible outcomes of uncertainty for their strategic choices [20].

- a tool used to arrange a person's perception regarding future alternative environments in which the outcome of their vision will play out [63],

- Realistic combinations of key driver values, which are constructed into fully-fledged narratives by enriching them with information about the dependent variables, the specific events, and the interactions between the many scenario elements [14].

Scenario development is essential must consider various options, not only those that are predictable and traditional in the organization [11]. Indeed, such encouragement is part of the process and will help to create new possibilities and different insights. Considering multiple possible scenarios; i.e. considering several future alternatives assist in conducting future planning in a holistic way [15], and drastically improves the ability to deal with the uncertainty and utility of the decision-making process global decision; [68]. The scenarios reached a completely new dimension in the early 70s with the Pierre Wack's work, who was a planner in the London offices of Royal Dutch/Shell (international petroleum group), resulting in a newly formed department called Group Planning [72].

For the scenarios to be drawn up, the scenarist, therefore, must consider a set of forces that act on the system in question. However, the considering of such forces should not be limited to the extrapolation of past trends. It is necessary to go further and adopt a pluralistic approach regarding the future, which is marked both by restraining forces and driving forces that run on the system's variables, as well as by the natural or social limitations within which the variables may evolve in the period of analysis. Uncertainty is a fundamental element to take into consideration when deciding on the use of the tool [6].

Godet $[34,35]$ defines prospective scenario as "the set formed by the description of a future situation and the course of events that enables one to progress from the original situation to the future situation". The author supplements his definition by including that, a scenario is not the reality of the future, but a means of representing it, with the goal of guiding present action considering possible and sought-after futures. Scenario planning is not an exercise in prediction, but an effort to make consistent and plausible descriptions of possible future situations.

The usage of scenarios causes the organization to think systematically and strategically about the variety of potential outcomes, without the influence of their own inclinations, opinions and preconceptions. For Godet [34, 35] scenario planning allows the organization to reflect on and rehearse the possibilities of tomorrow, and to avoid complacency or fear of changing something that is currently a favourable situation.

Schoemaker [59] points out that the scenario methodology can be employed in any situation of uncertainty, because it is used to identify early-warning signals, to evaluate the robustness of the core competencies of the organization, to generate better strategic options, and to evaluate the risk/returns of each option. According to Schoemaker [59], the use of scenarios is suitable under the following conditions [30].:

- When there is a high level of uncertainty regarding the ability to study the future;

- When a few surprises have occurred in the past;

- When there is possibility of there being new opportunities, which were not foreseen or generated;

- When an inferior quality of strategic thinking is detected;

- When the company needs a common language without losing its diversity; and,

- When there are various differing opinions.

The scenarios must consist of internally coherent views of future possibilities (often in the form of stories), which will be useful to predict the implications of uncertain developments. It helps participants of the decision-making process to organize their thinking regarding what would be the desired course to respond to conjuncture represented by the scenario, with the goal of increasing robustness in the policies and development strategies that will be adopted [38]. A key element that needs to be considered when deciding to use the tool is the uncertainty.

The essence of "business wisdom" is being mindful about the future of businesses [2]. Understanding it and controlling it is the big challenge for companies, especially in the age of knowledge, because when talking about the future, thinks in scenario. Therefore, the importance of planning with scenarios is confirmed. Modelling future scenarios has become a tool of civil and military intelligence agencies, of governments that employ strategic planning, and of large corporations, in addition to its countless scientific applications in the most varied fields, including meteorology, astronomy, environmental sciences, economics, marketing, finance and demography. Whoever prospects the future and acts proactively, will have a better chance of success than his competitors.

When planning using scenarios, you stay "a step ahead" of the more traditional planning methodologies, because the uncertainties are incorporated into constructing of the future. [8]. When planning with the use of prospective scenario, strategies are therefore developed to assist managers in the definition of the life of the organization 
through the most varied methodologies, and, as such, to better define the uncertainties of the environment to build a better future. Scenarios are working tools that provide guidance for companies and governments, since they serve as a point of reference for the analysing of alternatives and for subsequent decision making towards a strategic objective. At this point, we identify a clear synergy between MCDA and the study of scenarios.

When looking to the future, we must take into consideration three characteristics of knowledge: things we know that we know; things that we know that we don't know; and things that we don't know that we know.

The Table 1 shows the prospection pertains to the search of future possibilities and their prevision.

Table 1. Prevision and Prospection

\begin{tabular}{|c|c|}
\hline Prevision & Prospection \\
\hline $\begin{array}{c}\text { Focuses on the certainties and } \\
\text { conceals the uncertainties }\end{array}$ & $\begin{array}{l}\text { Focuses on the uncertainties } \\
\text { legitimizing their presence }\end{array}$ \\
\hline Originates from a single & Originates from diverse, but \\
\hline projection. & logical, images of the future \\
\hline $\begin{array}{l}\text { Gives preference to } \\
\text { continuity }\end{array}$ & $\begin{array}{l}\text { Gives preference to rupture } \\
\text { considerations }\end{array}$ \\
\hline $\begin{array}{l}\text { Qualitative influence is } \\
\text { minimal }\end{array}$ & $\begin{array}{c}\text { Seeks to align the qualitative with } \\
\text { quantitative }\end{array}$ \\
\hline The prediction may hide risks & $\begin{array}{c}\text { The various "futures" cause the } \\
\text { risks to show }\end{array}$ \\
\hline Can generate inertia & Gives preference to flexibility \\
\hline $\begin{array}{l}\text { Begin as simple models and } \\
\text { then become complex }\end{array}$ & $\begin{array}{l}\text { Is part of future, is complex, seeks } \\
\text { simplification. }\end{array}$ \\
\hline $\begin{array}{c}\text { Can generate a sectorial } \\
\text { approach }\end{array}$ & $\begin{array}{l}\text { From the beginning, it adopts a } \\
\text { comprehensive approach. }\end{array}$ \\
\hline
\end{tabular}

Source: European Commission [28].

The ability to look towards the future and "direct it" is part of the context of planning in organizations, and as some authors have noted $[15,35,63]$, the use of prospective scenarios is one of the most appropriate tools for the defining of strategies in turbulent and uncertain environments. With the building of multiple scenarios, a company can systematically explore the possible consequences of these uncertainties regarding its strategic options. Scenarios represent an understanding that is vital to guide strategic decision-making [35]. It is a means of enhancing the ability to visualize alternative futures.

Selecting the method of building scenarios and integrating it into the company's strategic process is an arduous task, which requires profound knowledge and commitment. The choice of methods will depend on the specific characteristics of each company, in other words, the strategic decisions, the work environment, the organizational culture, the time available, and the investment and expected outcome. It should be noted that the models are rarely used on their own, and often, they are combined. The authors of prospective studies have found that the organizations had many set objectives for prospective studies, ranging from "creating an early warning signal" to "building consensus". However, three main themes stood out:
- Generating information that contributes to the process of decision-making;

- Motivating people to reflect on the future; and,

- Bringing people together, to form a collective or shared vision of the future.

\subsubsection{Methods for Developing Scenarios}

There is no single approach to scenario development, literature reviews demonstrate that there are a variety of methodologies for such scenarios and these have common characteristics [12, 17, 46, 68]. Bradfield et al [12] and Chermack et al [17] verified several methodological approaches and guidelines presented in the literature for the construction of these scenarios. Bishop et al [8] also study more than a dozen scenario planning techniques and lecture on the usefulness, strengths, and weaknesses of these methodologies. The scenario-building models presented by Schwartz [62] and Schoemaker [59] are considered popular and frequently cited in the scenario planning literature [16, 17, 68]. Following is a description of the main methods used for developing scenarios.

Morphological Analysis: it is a technique, which configures, in a systematic way, all possible situations for a given system through the combination of different parameter statuses (characteristics) of that system. It was developed by Fritz Zwick and was implemented as of 1942 [76]. It stems from a given situation, and generates new situations through the restructuring of the initial situation, producing a great number of alternative configurations [59]. The system is structured on the development of the following stages:

- The system is defined as precisely as possible;

- Basic parameters (characteristics) of the system are analysed, described and identified;

- Each parameter is examined and which independent conditions (situations) it can take on are determined;

- Restrictions to eliminate inconsistent combinations are introduced; and,

- Alternative combinations between the conditions of each parameter, respecting the established restrictions are performed.

The methodology for building business scenarios is a technique developed to be applied to businesses, where the focus is elicitation of uncertainties to causal factors of the same. The system is structured on the development of the following stages:

- The uncertainties and the causal factors of the above are identified;

- The variables of each causal factor are identified;

- Combinations of variables to create scenarios are performed; and,

- The competitive advantages of each scenario are determined;

Scenario Method: developed by Godet [35], once the 
identification of the key variables for the study takes place the goal; once the problem has been clearly defined and these are associated with the strategic objectives, as well as with the actors that influence the process; it is to list possible scenarios $[34,35]$. The system is structured on the development of the following stages:

- The problem is determined;

- The key variables are identified and a retrospective analysis of the same is performed;

- The strategic objectives are defined, and which will be the actors involved is determined; and,

- Projections of scenarios are made.

Interax Method: This focus of this method is primarily on the use of indicators, as well as detecting impacting events [35]. The system is structured on the development of the following stages:

- Definition of main issue and period of analysis;

- Identification of key indicators;

- Projection of key indicators;

- Identification of impact of events;

- Development of probability distribution of the event;

- Estimative of impact of events on trends;

- Complete of cross-impact analysis (using the cross-impact matrix); and,

- Process of model.

Understanding that there are some advantages and disadvantages when choosing each of the techniques mentioned above, as well as when relating them to other concepts of decision making, Vieira et al [71] and Gomes et al [38] presents a hybrid approach, seeking to unify concepts presented by various methods. This approach is presented as Momentum, or Unified Strategic Prospective Planning method. The method uses tools like problem definition, SWOT analysis (or SWOT matrix is an acronym for strengths, weaknesses, opportunities, and threats), indicators and retrospective studies, cross-impact matrixes elaborations to build and evaluate scenarios. The Momentum approach is structured by the following stages:

- Understanding or overview of selected system or business, determining its inputs, outputs, mission and future vision, when applicable;

- Mapping of relevant actors, and their respective influences or areas of influence; Identification of variables, selecting the internal (strengths and weaknesses) and the external variables (threats and opportunities) of the system under study, performing a SWOT analysis;

- Elicitation of uncertainties, and their respective casual factors;

- Selection of relevant variables;

- Elaboration of variables retrospective, or historical analysis, to define variables settings and to assign their respective probabilities of occurrences;

- Definition of key indicators and perform of their retrospective analysis;
- Construction of scenarios, pursuing the most desired, or desirable, one and other scenarios which are pertinent;

At this point the decision maker can evaluate how each alternative operates in each scenario and can assign weights to each criterion for each scenario. With the integration of MCDA with prospective vision, it is recommended the decision-maker revaluate the weights/values that have been assigned to each criterion, once the future scenario becomes unforeseeable.

These decisions are those that influence and define the future of any company and the managers it is important to have the tools and knowledge that not only allow them to define strategies but to direct their actions, regardless of the size or complexity of the company [52].

The scenario planning practice allows the manager to be prepared for the future and to think about innovation possibilities, also allows the manager to check all the complex elements together in a coherent, extensive and systematic manner [46]. The prospective analysis in general is based on the premise of the complexity and the need to explore and understand the existing relationships in the system to establish the possible future alternatives. [61]

Increasing uncertainties have also elevated the importance of recognizing future trends and the business environment [3]. The scenario planning practice allows the manager to be prepared for the future and to think about innovation possibilities. Scenarios allow the manager to check all the complex elements together in a coherent, extensive and systematic manner. It was also possible to observe the relationship between scenario planning and innovation planning [57]. Inserted into the organizational culture, they provide managers with a strategic differential that, in addition to reducing risks in decision making and increasing the likelihood of success, allow the company to be more assertive in maintaining its business, as they offer better conditions of competitiveness and adaptation.

The use of scenarios for the long term, adding to the strategic planning vision, allows the organization to adapt more quickly to significant changes [68]. The greater uncertainty for planning, given the various situations in which the organization will be subject, occurs the expansion of future possibilities.

Scenario planning has been widely used at the corporate level. Planning through scenarios helps organizations test their strategy. At the corporate level, Shell is considered the most famous and best-known company in the use of scenarios in the world in the context of business and the use of this tool helped the company to deal with the oil shock in 1970 , in addition to other uncertain events $[17,46,60]$

The process of scenario construction also contributes to organizational learning [16]. The main benefits of using scenarios are improving the decision-making process and identifying new issues and problems that may arise [68]. In the literature, scenario planning has different meanings for different users and often developed for different purposes 
[9]. Scenarios are developed for different audiences, since different stockholders are involved, and should adequately match their needs.

Planning by scenario does not mean predicting the future, but exploring the various possible future situations to broaden the thinking sphere of the participants in the scenario development process $[35,69]$.

Some researchers believe that the use of scenario planning is limited in scope because scenario methods have not evolved into a set of more simplified sub-techniques, that is, their application is considered complex and difficult to implement and often requires assistance of sophisticated software tools [12].

\subsection{Multicriteria Decision}

In real decision-making situations, several possible solutions can be considered, which forces the manager to evaluate different points of view. This fact corroborated the emergence of a tool that could support him in his decisions. This type of approach, called Multicriteria Decision Support or decision-making problems, refers to decision-making in the presence of multiple, often conflicting, criteria.

Decision-making is sometimes a complex and difficult task, especially when it involves finding best alternative, that is an option, a choice, or an action, or ranking all alternatives in the presence of multiple, usually conflicting criteria.

Decisions are necessary when there is an opportunity or a problem, or when something is not as it should be, or when there is an opportunity for improvement or optimization. A lack of understanding about how decisions are taken, how processes are implemented, and what results to expect, raises obstacles for effective IT governance. The absence of a formal and rational method will lead the decision-making process and the respective decisions to be based on policies, opinions and emotions, at the expense of facts and objective criteria.

Saaty and Ergu [55] state that the components for a decision include: an in-depth understanding of the chosen problem so doubts and uncertainties are minimized; the creation of a structure that represents the factors involved in the criteria and alternatives; a scale to represent judgments; and the priorities generated through numeric judgements.

Further describe that the following aspects should be involved in quality decision-making:

a. A perception of the decision-maker regarding the necessity and appropriateness of the decision, considering marketing, operational, technological, strategic, financial variables etc.;

b. The adoption of a methodology or combination of methodologies, enabling the identification of the variables and a rational analysis of the information; and c. The assessment of the necessity and feasibility of sharing the decision-making process to ensure the required engagement in the deployment of the chosen alternative. Multicriteria decision making and analysis methods are applied when there is a need to select, sort, classify or describe the present alternatives in a complex decision-making process with multiple criteria and conflicting objectives.

The models based on multi-criteria decision are recommended for problems where there are several evaluation criteria to consider. MCDA can also be defined as a set of techniques which are designed to search for many alternatives within multiple criteria and conflicting objectives [36-38]. A multi-criteria approach features the following advantages [36]:

- Creates a platform for dialogue between analysts and decision makers who make use of common viewpoints;

- Provides an easy way of incorporating uncertainties about the data on each point of view;

- Enables facing each alternative as a commitment between conflicting objectives. This argument highlights the fact that there is rarely a situation in which an alternative is found that it is superior to all the alternatives remaining on every point of view.

Since the decisions are dynamic, the decision-makers must be convinced that the process of analysis is conducted properly and thoroughly to allow them to estimate the potential result of their decisions. This explains the growing demand for approaches based on MCDA or multiple criteria decision making (MCDM), and it also explains the increase in the adoption of models to support the decisions that occur in situations of uncertainty and risk [47]. Multi-criteria methods can be divided into three main approaches regarding the principles of modelling preferences, as follows:

- Single synthesis criterion approach: consists of bringing together different points of view within a single synthesis function, which can be subsequently optimized. In this case, the conditions of aggregate functions and model building should be analysed. The Multi-Attribute Utility Theory (MAUT) is an example [36].

- Outranking Approach: sometimes known as the French School of decision-making, first supports constructing outranking relations to represent the decision-makers' preferences. The next step consists of exploring outranking relations to help decision-makers solve the problem. Some examples are the ELECTRE (ELimination Et Choix Traduisant la REalité, in English: ELimination and Choice Expressing Reality) family methods. Often, methods which contain approaches for overcoming is used in order to select a subset of a finite set of alternatives or to rank order them. Mainstream methods do not allow 
the unlimited compensation of "large disadvantages" and in addition, consider the fact that small differences between evaluations of the alternatives are not always significant [36-38].

- Interactive Judgment Approach: methods that use a trial and error approach and multi-objective mathematical programming structures. The continuous methods are also called multi-criteria optimization methods or interactive methods, which involve mathematical optimization methods for problems involving more than one objective function. The approach to problem solving under the MCDA focus is not intended to provide decision-makers with a solution to their problem, but rather, chooses a single truth represented by the selected action. It aims to aid the decision-making process by recommending actions or courses of actions to those who will make the decision. [36].

The MCDM is dedicated to the modelling of decision problems based more on the use of mathematical models, which require enough robustness of the model to support axiomatic validations, seeking an aggregation function; being this a "limiting factor" for its application to modelling in certain situations that involve "great subjectivity and uncertainties". The second part, MCDA, presents itself as an alternative for the modelling of problems in which subjectivity and uncertainties are preponderant in a non-compensatory environment.

Ferretti [31] states that the operationalization of decision-making tools has obstacles that need to be highlighted, such as multiple stakeholder views, which require a participatory decision-making process that can include different perspectives, long horizons, which have their intrinsic uncertainty; besides these Tsoukias et al. [67] adds the need for legitimization and accountability of results and processes. The need for multicriteria evaluation, to establish a support structure for decision making, is then applied [50]. Numerous MCDA methods can be applied to specific models to solve the problem of selection of the optimal set of projects.

\subsection{Search in the ISI base}

The study was developed from Institute for Scientific Information (ISI) databases via access through CAPES Journals using the term "multicriteria and decision". The survey was consolidated in January 2016 and the results were organized into tables and graphs to facilitate presentation and analysis.

It is a quantitative approach of the scientific production on the multicriteria and decision theme, highlighting the year of publication, the area of knowledge, the methods used and the main authors.

The ISI database searches were conducted from the fields of Science Technology, Social Sciences, and Arts and Humanities. This resulted in a total of 3,629 records, of which 2,406 were papers. Table 2 presents the author distribution with the highest number of publications:

Table 2. Author distribution

\begin{tabular}{cc}
\hline Author & publications \\
\hline Tzeng, G. H. & 40 \\
Zavadskas,E.K. & 37 \\
Zopounidis, C. & 24 \\
Doumpos, M. & 18 \\
Ye, Jun & 16 \\
Salminen, P. & 15 \\
Martel, J. M. & 16 \\
\hline
\end{tabular}

Source: Authors from ISI (2017).

Per Table 2, the research is shared by several authors and, therefore, there is not a single author that concentrates the publications in the area. It can be observed that 2,280 papers were written in English, representing the majority (92\%), 49 in Portuguese, 32 in French, 28 in Spanish and 17 in Russian. Table 3 shows the publication distribution per the countries that publish the most:

Table 3. Publications distribution by country

\begin{tabular}{cc}
\hline Country & publications \\
\hline United States of America & 356 \\
\hline China & 159 \\
\hline Taiwan & 146 \\
\hline Brazil & 145 \\
\hline France & 135 \\
\hline Total & 941 \\
\hline
\end{tabular}

Source: Authors from ISI (2017).

Among the five countries that publish the most in the area, the United States of America leads with 356 publications. Then, China, with 159 , reaches $45 \%$ of the United States of America' production. Taiwan and Brazil have practically the same amount, reaching $40 \%$ of the production, while France, with 135, reaches 38\%, compared to the first place. Table 4 shows journal distribution with the highest number of papers (above 12):

Table 4. Publications distribution by journal

\begin{tabular}{cc}
\hline Journals & papers \\
\hline European Journal of Operational Research & 198 \\
Expert Systems with Applications & 99 \\
Journal of Operational Research Society & 34 \\
Journal of Optimization Theory and Applications & 33 \\
Computers Operations Research & 29 \\
International Journal of Production Research & 28 \\
Fuzzy Sets and Systems & 27 \\
Annals Operations Research & 27 \\
Omega International Journal of Management Science & 26 \\
International Journal of Intelligent Systems & 23 \\
Lecture Notes in Computer Science & 22 \\
Journal of Environmental Management & 16 \\
Environmental Management & 12 \\
\hline
\end{tabular}

Source: Authors from ISI (2017).

The European Journal of Operational Research stands out with the most papers, twice as many publications compared to the second place (Expert Systems with Applications). Table 5 shows publication distribution by research area: 
Table 5. Publication concentration areas

\begin{tabular}{cc}
\hline Research area & publications \\
Operations Research Management Science & 703 \\
Engineering & 697 \\
Computer Science & 567 \\
Business Economics & 497 \\
Eathematics & 441 \\
Environmental Sciences Ecology & 283 \\
\hline
\end{tabular}

Source: Authors from ISI (2017).

The total number of publications by research area differs from the total found, as some papers are positioned in more than one area. The largest total found refers to the Operations Research Management Science area, followed by Engineering by a small difference. Table 6 shows the applications of the methods used:

Table 6. Methods and theories applied in the database

\begin{tabular}{|c|c|c|c|}
\hline Method & Publications & Percentage & Accumulated sum \\
\hline Logic Fuzzy & 486 & $39.32 \%$ & $39.32 \%$ \\
\hline Analytic Hierarchy Process (AHP) & 234 & $18.93 \%$ & $58.25 \%$ \\
\hline GIS & 159 & $12.86 \%$ & $71.11 \%$ \\
\hline TOPSIS (Technique for Order Preference by Similarity to the Ideal & 133 & $10.76 \%$ & $81.87 \%$ \\
\hline $\begin{array}{l}\text { PROMETHEE (Preference Ranking Organization METHod for Enrichment } \\
\text { of Evaluations) Family }\end{array}$ & 116 & $9.39 \%$ & $91.26 \%$ \\
\hline ELECTRE Family & 108 & $8.74 \%$ & $100 \%$ \\
\hline Total & 1,236 & $100 \%$ & - \\
\hline
\end{tabular}

Source: Authors from ISI (2017).

Table 7 shows the relation between the research areas and the methods evidencing the total number of papers. Roman Numerals (I to VII) indicate the position per the most cited method by area.

Table 7. Area and method relation

\begin{tabular}{|c|c|c|c|c|c|c|c|}
\hline & AHP & $\begin{array}{l}\text { Logic } \\
\text { Fuzzy }\end{array}$ & $\begin{array}{c}\text { ELECTRE } \\
\text { Family }\end{array}$ & GIS & PROMETHEE Family & $\begin{array}{l}\text { Multi-objective } \\
\text { Optimization }\end{array}$ & TOPSIS \\
\hline \multirow{2}{*}{ Engineering } & 91 & 175 & 34 & 29 & 33 & 41 & 53 \\
\hline & II & I & $\mathrm{V}$ & VII & VI & IV & III \\
\hline Computer & 59 & 239 & 29 & 22 & 22 & 28 & 57 \\
\hline Science & II & I & IV & VI & VI & $\mathrm{V}$ & III \\
\hline Environmental & 37 & 38 & 18 & 77 & 17 & 0 & 10 \\
\hline Science & III & II & IV & I & $\mathrm{V}$ & VII & VI \\
\hline \multirow{2}{*}{ Mathematics } & 20 & 95 & 6 & 0 & 18 & 0 & 23 \\
\hline & III & I & $\mathrm{V}$ & VI & IV & VI & II \\
\hline Total & 207 & 547 & 87 & 128 & 90 & 69 & 143 \\
\hline
\end{tabular}

Source: Elaborated by the authors from the source ISI (2017).

It can be observed that the Logic Fuzzy method is the most used, except in the Environmental Science area where the GIS method is the most applied. The Analytic Hierarchy Process (AHP) method is the second most used in the Engineering and Computer Science areas, falling to the third position in relation to Environmental Science and Mathematics.

The study proved to be the most applied AHP for engineering problems. The AHP for being hierarchical is in accordance with military culture. For these reasons was the method adopted.

\subsection{Analytic Hierarchy Process (AHP)}

The AHP, was developed by Tomas L. Saaty in the early 1970s [66] and it is the most widely used and known multicriteria method, as previously noted, in Table 6 .

Allocating the weight or importance to everyone with in a group is an important component in the decision process and plays a key role in obtaining the final solution in an AHP model [23].

Such a method is based on the Newtonian and Cartesian principle of thought structure, which treats complexity with the decomposition and division of the problem into factors, which can be further decomposed into new factors until they become clear and scalable, that is, when there is its simplification. This method is based on three steps of analytical thinking:

i. Hierarchical construction: in the AHP method the problem is presented at hierarchical levels, making it easy to understand and analyse. For the use of this methodology it is imperative that the criteria and the alternatives be structured hierarchically. Figure 1, which presents the basic hierarchical structure of the AHP method, illustrates well the decomposition of criteria into alternatives. The first 
level of the hierarchy corresponds to the general purpose of the problem, the second to the criteria and the third to the alternatives. Per Bornia and Wernke [10], the hierarchical arrangement allows the "visualization of the system and its components, as well as interactions of these components and the impacts they have on the system".

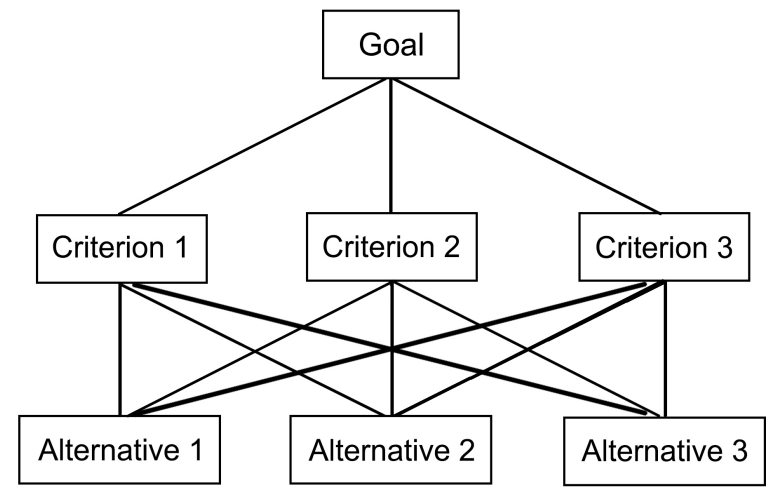

Source: Saaty, Vargas [54]

Figure 1. AHP hierarchical structure model

ii. Priority definition: At this step it is necessary to judge elements of a hierarchy level together, composing the judgment matrices using the scales presented in Board 2. The practice of decision making is related to the evaluation of the alternatives, all of which satisfy the conditions imposed and the intended objectives. However, it is necessary to understand what the judgments are in the method created by Saaty so that the scale of priorities can be used appropriately. Such judgments are represented in a square matrix, in which the elements are compared with themselves. The scale recommended by the creator of the method ranges from 1 to 9 , with "1" being the indifference of importance of one criterion over the other, and "9" the extreme importance of one criterion over another, with intermediate steps of importance between these levels 1 and 9. The comparisons between the criteria themselves, which represent "1" on the scale, are disregarded. Only half of the comparisons are performed, since the other half consists of the reciprocal comparisons in the comparison matrix, which are the reciprocal values already compared. Grandzol [40] describes that through these comparisons in pairs, and per the AHP priority scale, stakeholders develop relative weights to differentiate the importance of the criteria. The number of judgments required to construct a generic judgment matrix $A$ is $[n .(n-1) / 2]$, for $n_{x} n$ matrix, $n$ being the number of rows and columns [66]. The elements of $A$ are defined by the conditions described in Figure 1.

iii. After elaborating the judgment matrix, it is necessary to normalize it, for this, the sum of the elements of each column of the matrices of judgment and subsequent division of each element of these matrices by the sum of the values of the respective column.

iv. Logical consistency: the human being can establish relationships between objects or ideas so that they are coherent, such that they relate well to each other and their relationships present consistency $[54,55]$

v. Following this line of reasoning, the method studied here, the AHP, proposes to calculate the Consistency Ratio of the judgments, or RC = IC / IR, where IR and the Random Consistency Index obtained for a reciprocal matrix of order $\mathrm{n}$, with non-negative elements and randomly generated.

The Consistency Index (IC) is given by $\mathrm{IC}=(\lambda \max -n) /$ (n-1), where $\lambda \max$ is the largest eigenvalue of the judgment matrix. Per Saaty $[54,55]$ the condition of consistency of the judgments and $\mathrm{RC} \leq 0.10$. Saaty $[54,55]$ proposes a table with random indexes (IR) of matrices of order 1 to 15 calculated in the laboratory, as shown in Table 8 and Table 9.

Table 8. Numerical scale, verbal scale explanation of Saaty

\begin{tabular}{|c|c|c|}
\hline Intensity of importance & Definition & Explanation \\
\hline 1 & Equal Importance & Two factors contribute equally to the objective \\
\hline 3 & Somewhat more important & Experience and judgment slightly favour over the other \\
\hline 5 & Much more important & Experience and judgement strongly favour one over the other \\
\hline 7 & Very much more important & $\begin{array}{l}\text { Experience and judgment very strongly favour one over the other. Its } \\
\text { importance is demonstrated in practice }\end{array}$ \\
\hline 9 & Absolutely more important & The evidence favouring one over the otter is of the highest possible validity \\
\hline $2,4,6,8$ & Intermediate values & When compromise is needed \\
\hline
\end{tabular}

Source: Adapted Xi Xi, Qiuli Qin [74].

Table 9. Random indexes proposed by Saaty.

\begin{tabular}{ccccccccccccc}
\hline Matrix size & 1 & 2 & 3 & 4 & 5 & 6 & 7 & 8 & 9 & 10 \\
\hline Mean random inconsistency & 0.00 & 0.00 & 0.58 & 0.90 & 1.12 & 1.24 & 1.32 & 1.41 & 1.45 & 1.49 \\
\hline
\end{tabular}




\section{Methodology}

Per Vervoorta et al [70] the main questions are:

- How can the imagination be freed to create powerfully engaging and meaningful future scenario worlds?

- How may imaginative scenario processes make the deep, essential mutability of the future productive?

- How may they trace, foreground and operationalize the mutuality of futures with the present?

- How may we encourage those participating in scenario-based processes to breach the limitations implied by current circumstances, and, by extension, shed the debilitating effects of the social, political, economic and environmental status quo?

This paper suggests answers this questions with a theoretical foundation is based on bibliographical research, beside important databases of available journals. The proposed model is supported by three theoretical pillars combined:
i. Strategic Planning;
ii. Future scenarios elaboration and
iii. MCDA integrated prospective, with the intention of treating subjectivity considering several possible criteria, forcing the manager to evaluate different perspectives.

\subsection{Strategic Planning}

In the model proposed here, it is intended to provide conditions for the manager to seek the most appropriate strategic planning for his company, for that, it is necessary to know, comprehensively, the company and the environment in which it is inserted. The concept of the model has the strategy as a direct and one-to-one relation to the company and the external environment.

The details of the company will be carried out by exploring the strengths and weaknesses as well as in the S.W.O.T. analysis, when analysing the internal environment. On the other hand, the exploration of the external environment will take place by the PEST analysis.

Created by Kotler [48], the PEST analysis aims to detail the external environment in which the company operates, PEST is an acronym for: P - Policy; E - Economic; S Social; And T - Technology. Such factors play an important role in the value creation opportunities of a strategy, but are outside the control of managers and, in parallel with S.W.O.T. are the threats or opportunities.

\subsection{Future Scenarios Elaboration}

The model proposed in this work is based on the methods proposed by Schoemaker [59], entitled Decision Strategies International, which consists of ten steps, where the author recommends developing two extreme scenarios (optimistic and pessimistic scenarios) [58 - 60]; and
Unified Method of Prospective Strategic Planning [37]. In general, these scenario-building techniques emphasize problem definition by identifying key factors, stakeholders, trends, constraints and other important issues in a systematic manner and classifying such items by importance and uncertainty. Gomes et al [37] presents a nom compensatory multicriteria method. This problem presents a compensatory and Hierarchical problem.

The usefulness of quantitative methods decreases, while the usefulness of qualitative approaches increases. Figure 2 shows the progressive reduction of the usefulness of quantitative methods. Therefore, the qualitative and quantitative approaches are complementary and have as important variable the future time to be studied, whether short, medium or long term.

The choice of the methodology for the elaboration of the scenario to be used varies per the established purpose. There is no consensus in the literature regarding a typology of scenarios. However, they also recognize that having more than one typology or methodology can be useful, since each proposal has different purposes. Thus, the authors proposed a typology that aims to emphasize how the scenarios are used and can be observed in Table 10. Such typology is based on the three main questions that, per them, could be asked about the future: "What will it happen?", "What can it happen?" and "How can a specific goal be achieved?". Each of these three questions composes distinct types of scenarios, which have two subtypes each [9].

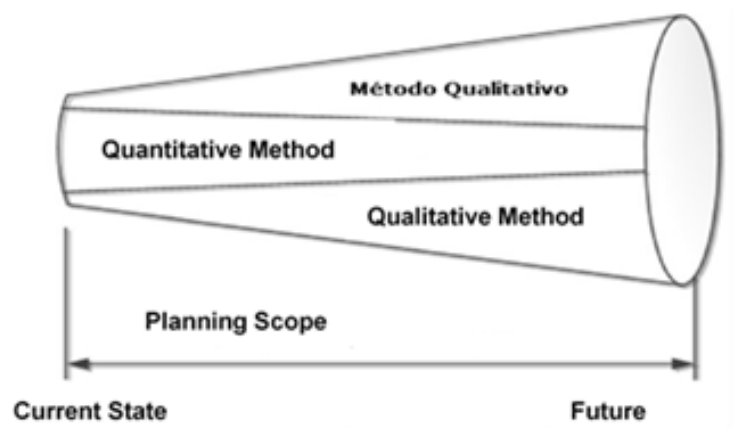

Figure 2. Comparison of qualitative and quantitative analyses for the Source: Adapted from Pillkahn (2008)

Table 10. Scenarios typologies according to their use

\begin{tabular}{cc}
\hline What will happen? & Forecast \\
\hline Predictive scenario & What If? \\
What could it happen? & External \\
Exploratory Scenario & Strategically \\
How can it achieve as specific goal? & Preservers \\
Normative Scenario & Changers \\
\hline
\end{tabular}

Source: Adapted Souza \& Takahashi [65]

The scenarios are classified into prospective or prognostic (from past to future) and retrospective or retro gnostic (from the future pre-established to the present) [65]. In Figure 3, there is the illustration of this. 
Prospective scenarios

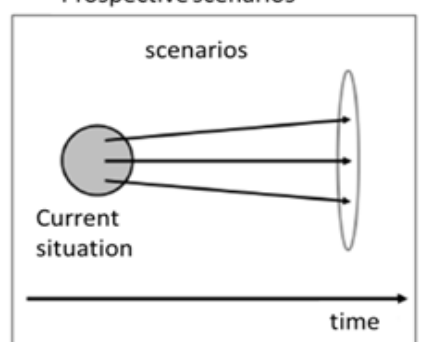

Retrospective scenarios

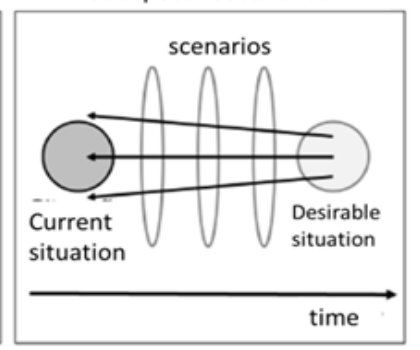

Source: Adapted from Souza \& Takahashi [65]

Figure 3. The sense of the projection of prospective and retrospective scenarios

There is no precise answer in the literature to the question of how many future scenarios are ideal for scenario planning [3]. Durance and Godet's [26] recommendation is the development of a quantity around 4 (four) scenarios, since they affirm that the amount of possible combinations would be very great. However, approaches with two scenarios might be quite simplistic and end up ignoring some subtleties or important details. Bezold [7] suggests the approach of three scenarios, considering the most probable (expected scenario), one that can go wrong (pessimistic scenario) and visionary possibilities (optimistic scenario).

\subsection{MCDA Integrated Prospective}

To be possible, then the understanding of the proposed model, each of the 6 steps proposed here will be described below, and will be detailed in 6 steps:

- System Definition

- Identification of factors that impact the System;

- Construction of the scenarios;

- Creation of investment alternatives;

- Application of multicriteria aid to the decision; and

- Definition of the investment alternative.

Step 1 - System definition:

Because it is a model that has its conception based on the aid to the management of companies, for this proposed model, it makes more sense that they are considered companies/organizations, when of the "System Definition". It is possible, without prejudice to the result, to choose any companies, be they from the first, second or third sector, since this is strategic planning. In the present work, it will be considered a company/organization of engineering services.

Still in this step of definition must be identified:

(a) Inputs - know the history of the company, the environment in which it is inserted, the need to apply the tool and other data that are necessary for the contextualization of the same.

(b) Detail of internal and external environments - will be carried out through the exploration of strengths and weaknesses as well as in the S.W.O.T. analysis, when analysing the internal environment. The exploration of the external environment will take place through the PEST analysis.

(c) Mission and Vision - identifying the Mission and Future Vision of the company.

(d) Main stakeholders - stakeholders.

Step 2 - Identification of factors that impact the System

Because this step being necessary for delimiting the internal and external environments; this step being the input for the elaboration of scenarios, and considering that the quantity of factors obtained is very large, knowing the most significant factors becomes essential. For this, an Impact versus Dependence Matrix, known in the literature as the Matrix of Cross-Impacts must be elaborated.

This resource has been widely used as a planning method for future scenarios since its creation by Gordon and Helmer in 1966 [3]. Its main objective is to identify the possible occurrences and how much this can impact the other events. Thus, the factors that most impact and/or are impacted by each other are identified, and factors that do not impact or are not impacted are excluded.

\section{Step 3 - Construction of the scenarios:}

To comply with this step of the model, which aims to explore the main factors capable of impacting the system, a morphological analysis will be performed. Fritz Zwicky proposed this type of analysis in the 1960s to explore all possible solutions to a multidimensional and non-quantifiable problem (AMER et al, 2012). The morphological analysis was used by several researchers in the field of future studies and development of scenarios [9, 26]. This process is considered an improvement for the selection of scenarios and for their detailing [25]. Jenkins [45] recommends the use of morphological analysis to eliminate incompatible combinations of factors and to create plausible combinations. From the proposed analysis, three of the scenarios foreseen in the trend, optimism and pessimistic model will be created. From these, another scenario is proposed, the integrated scenario, which aims to consider the previously considered factors in an isolated way in each of the scenarios resulting from the morphological analysis. It should be noted that if it is necessary to test other scenarios beyond the four proposed, or if interested parties have such a need, these can be obtained in the combination of the proposed morphological analysis or in the extrapolation of their data. However, as explained in section 3.2 of this paper, the construction of many scenarios above 4 can make this analysis too expensive and laborious, and is not applied in the model proposed here

\section{Step 4 - Creation of investment alternatives}

After completing the previous steps, it is possible to glimpse the company positioned somehow in the future, by reading the Trend, Optimistic and Pessimistic Scenarios 
(Step 3) and the company's positioning in the environment (Steps 1 and 2), from therefore the stakeholders in the business have a basis for indicating realistic investment alternatives, meeting what is proposed at this step.

\section{Step 5 - Application of multicriteria aid to decision}

In this step the chosen multicriteria method, AHP or Analytic Hierarchy Process must be applied, per the theoretical reference of this work. Its use will have the main objective of standardizing the criteria indicated for the evaluation of the investment alternatives (Step 4). Its application will have the objective of prioritizing the evaluation criteria of investments, and in each scenario prospected.

First, the criteria for the evaluation of alternatives must be chosen and defined (Step 5); subsequently, the scales should be defined for each criterion. It should be clarified that some specific characteristics of the AHP method, made it the one chosen for its application in the model to the detriment of another method, such as the possibility of judgments of problems with several criteria and alternatives, there is no need for processing of the data before its use, allow to evaluate the consistency of the judgments, the existence of free software for its application and test, there is no need for a specialist, given its ease of application.

Considering that the objective of the proposed model is an aid tool for the elaboration of strategic planning, and the complex environment of competition in the companies acting and the need for easy response to changes in the environment, AHP has proved to be a good alternative.

\section{Step 6 - Definition of the investment alternative}

After all the completed steps, having considered all the variables defined in the proposed model, the investment alternatives will be ranked. That is, the alternative can be verified with a higher or lower score, it is then up to the stakeholders to define the best investment option(s), since this will guide the company's strategic planning.

In this step, the MAUT should be used to establish the attractiveness of each investment alternative. It should be noted that utility theory is considered as the representation of the relative preferences of an individual among the elements of a set, using real numbers to represent them

Utility is a quantitative expression of the satisfaction value associated with a result describe the traditional methods of max-max analysis, where in each state of the future nature the best of each alternative is selected, and subsequently the best of the maxima is chosen; The method called Laplace, where the highest of the means is selected, and the Minimum Repentance (Marrp) method, where the alternative that minimizes repentance is chosen. For the model proposed here, these possibilities of choice should be considered per the profile of the manager, if conservative in his decisions.

\section{Results}

For the reader to know the company and the environment in which it operates, a descriptive research was carried out, to collect the necessary data for the application of the model proposed here. Such research was conducted through meetings with the operations manager and the financial manager. The company studied here was chosen for the application of the model by the author's ease of access to it; thus, mitigating delimitations already exposed in the introduction of this study.

\subsection{Step 1 - System Definition}

The company studied in this research will be the XPTO. The managing partners preferred, for information security measures, not to be identified. Its headquarters is in Niterói and its branches in the municipalities of Rio Bonito and Duque de Caxias, respectively, all in the State of Rio de Janeiro, Brazil.

It is a consulting engineering company, which provides outsourcing services for the oil and gas sector and has as its only client a Brazilian oil \& gas energy corporation.

XPTO is an ISO 9001, ISO 14001 and OHSAS 18001 certified company and works in an Integrated Management System environment, guaranteeing standardization of processes and focus on continuous improvement in quality, environment and safety and health at work. To provide services to its sole customer, XPTO must be included in its supplier register and comply with the requirements of that state company. The higher the score, the more likely you will be invited to bid. In this way, XPTO receives an average of 450 invitations a year to participate in bids with its client.

For XPTO to provide services, it is necessary to win the bidding process, where the first indicator will be the best price and afterwards, its classification will be given through clarification regarding its budget as well as fulfilment of some requirements. Once the entire bidding process is over, the company will be a winning winner and will manage a contract that has several predetermined specifications, term, cost and object. It should be noted that this information was taken from the Integrated Management System Manual (SGI, in Portuguese), which is included in its revision September the $3^{\text {rd }}, 2015$; which is the most current revision to date.

The company XPTO has a fixed structure of approximately 30 employees that act directly or indirectly in the activities of support for the management of the contracts. Its division is composed of seven departments made up of managers and their assistants, namely: Administrative, Budget, Human Resources, SMS (Environment and Health Security), Contracts, Planning and Development (R\&D) and Financial. These departments act in an integrated manner and report directly to the Board of Executive Officers. The Contracts department is the one who interfaces with the customer at all steps of contract management. In addition to the fixed 
It should be noted that items 2, 3, 4 and 9 are the items located in the third quadrant of the graph and represent those that significantly impact the environment in which the XPTO Company is inserted were the highlight in the elaboration of the scenarios. On the other hand, factors 10 , 13, 14 and 15 were excluded and will not be considered for Morphological Analysis, since they are in the first quadrant, which does not impact or is impacted and therefore will not be considered.

\subsection{Step 3 - Construction of the Scenarios}

After the previous steps completed, qualitative and quantitative assessments are carried out, which are the most relevant factors that must be considered when constructing the scenarios. Following its elaboration, a morphological analysis of these factors is performed; it is worth mentioning the application of such a technique to explore all possible solutions to a multidimensional and non-quantifiable problem that has been used by several researchers in future scenarios $[9,19,26]$.

Table 12. Morphological Analysis

\begin{tabular}{|c|c|c|c|c|}
\hline \multirow{2}{*}{ Id. } & \multirow{2}{*}{$\begin{array}{l}\text { Identified } \\
\text { Factors }\end{array}$} & \multicolumn{3}{|c|}{ Hypotheses of Scenarios - Horizon of 3 Years } \\
\hline & & Trend $\left(\mathrm{S}_{1}\right)$ & Optimistic $\left(\mathrm{S}_{2}\right)$ & Pessimistic $\left(\mathrm{S}_{3}\right)$ \\
\hline 1 & $\begin{array}{l}\text { Financial } \\
\text { soundness }\end{array}$ & 1.1 Reduce financial strength & $\begin{array}{l}\text { 1.2 To remain financially } \\
\text { sound }\end{array}$ & $\begin{array}{l}1.3 \text { To lose solidity and be forced to } \\
\text { take loans to fulfil their commitments. }\end{array}$ \\
\hline 2 & Lean prices & 2.1 Practice market prices. & $\begin{array}{l}2.2 \text { To maintain leaner prices } \\
\text { than its direct competitors. }\end{array}$ & $\begin{array}{l}\text { 2.3 It cannot compete on price with its } \\
\text { direct competitors }\end{array}$ \\
\hline 3 & $\begin{array}{l}\text { Processes with } \\
\text { low error rates }\end{array}$ & $\begin{array}{l}\text { 3.1 Maintenance, since there will be } \\
\text { permanence of employees with } \\
\text { know-how. }\end{array}$ & $\begin{array}{l}\text { 3.2 Zero error indexes, with } \\
\text { the use of software's that } \\
\text { guarantee such rate. }\end{array}$ & $\begin{array}{l}3.3 \text { The number of errors in the } \\
\text { processes increased by the low number } \\
\text { of employees (result of layoffs) }\end{array}$ \\
\hline 4 & $\begin{array}{l}\text { Solidity in the } \\
\text { staff (Staff); }\end{array}$ & $\begin{array}{l}\text { 4.1 Small reduction of the frame, with } \\
\text { maintenance of know-how acquired. }\end{array}$ & 4.2 Maintenance of staff. & $\begin{array}{c}\text { 4.3 Great reduction of the staff, losing } \\
\text { part of the know-how acquired in the } \\
\text { market. }\end{array}$ \\
\hline 5 & $\begin{array}{l}\text { Economy of } \\
\text { scale }\end{array}$ & $\begin{array}{l}\text { 5.1 Reduction of the possible economy } \\
\text { when there are several contracts in force, } \\
\text { given the sharing of direct labour. }\end{array}$ & $\begin{array}{l}5.2 \text { Use of economies of scale } \\
\text { in price formation by making } \\
\text { them competitive. }\end{array}$ & $\begin{array}{l}5.3 \text { Few existing contracts, not } \\
\text { allowing the sharing of labour, } \\
\text { resulting in a high price load, in } \\
\text { isolation. }\end{array}$ \\
\hline 6 & $\begin{array}{l}\text { International } \\
\text { Certification } \\
\text { (ISO, OHSAS) }\end{array}$ & $\begin{array}{l}\text { 6.1 Maintenance of Certifications } \\
\text { (Integrated Management Systems) }\end{array}$ & $\begin{array}{l}\text { 6.2 Maintenance of } \\
\text { Certifications (Integrated } \\
\text { Management Systems) }\end{array}$ & 6.3 Loss of Certifications \\
\hline 7 & $\begin{array}{l}\text { Standardization } \\
\text { of activities and } \\
\text { processes }\end{array}$ & $\begin{array}{c}\text { 7.1 Maintain standards in activities and } \\
\text { processes. }\end{array}$ & $\begin{array}{l}\text { 7.2 Elaboration of new } \\
\text { standards that allow } \\
\text { advantages over competitors } \\
\text { and even service to our niches. }\end{array}$ & $\begin{array}{l}\text { 7.3 The changes in activities are abrupt } \\
\text { to the point of generating the need for } \\
\text { new procedures not yet elaborated, } \\
\text { resulting in waste and lack of control } \\
\text { in the process. }\end{array}$ \\
\hline 8 & $\begin{array}{l}\text { Small client } \\
\text { portfolio }\end{array}$ & $\begin{array}{l}\text { 8.1 The Brazilian oil \& gas energy } \\
\text { corporation maintenance as sole } \\
\text { customer. }\end{array}$ & 8.2 Capturing new customers. & $\begin{array}{l}\text { 8.3 The Brazilian oil \& gas energy } \\
\text { corporation maintenance as sole } \\
\text { customer and reduction of contracts. }\end{array}$ \\
\hline 9 & $\begin{array}{l}\text { Provision of } \\
\text { services in a } \\
\text { single division } \\
\text { of the client. } \\
\text { The Brazilian }\end{array}$ & $\begin{array}{c}\text { 9.1 Maintenance of service to this single } \\
\text { division. }\end{array}$ & $\begin{array}{l}\text { 9.2 Service to other divisions } \\
\text { of the company. }\end{array}$ & $\begin{array}{l}\text { 9.3 Extinction of the service sector and } \\
\text { demand for services, due to the } \\
\text { contractor's restructurings. }\end{array}$ \\
\hline 11 & $\begin{array}{l}\text { oil \& gas } \\
\text { energy } \\
\text { corporation } \\
\text { restructuring } \\
\text { customer }\end{array}$ & 11.1 To be consolidated. & $\begin{array}{l}11.2 \text { Managers with good } \\
\text { relations with the company } \\
\text { have decision-making power. }\end{array}$ & $\begin{array}{l}\text { 11.3 Not being consolidated and there } \\
\text { are several managerial exchanges, } \\
\text { generating uncertainties in the market. }\end{array}$ \\
\hline 12 & $\begin{array}{l}\text { The Brazilian } \\
\text { oil \& gas } \\
\text { energy } \\
\text { corporation } \\
\text { political and } \\
\text { financial crisis }\end{array}$ & 12.1 Maintenance & $\begin{array}{l}\text { 12.2 Emerging new } \\
\text { investments }\end{array}$ & $\begin{array}{l}\text { 12.3 Worsens to the point of no } \\
\text { investment. }\end{array}$ \\
\hline 14 & $\begin{array}{l}\text { Entry of new } \\
\text { competitors. }\end{array}$ & $\begin{array}{l}\text { 14.1 Reduction of current competitors, } \\
\text { given the crisis; And the emergence of } \\
\text { new competitors (big companies) that } \\
\text { will begin to operate in this area. }\end{array}$ & $\begin{array}{l}14.2 \text { Reduction of current } \\
\text { competitors, given the crisis. }\end{array}$ & $\begin{array}{l}\text { 14.3 Reduction of current competitors, } \\
\text { given the crisis; the emergence of new } \\
\text { competitors (big companies) that will } \\
\text { dominate this branch of activities. }\end{array}$ \\
\hline 16 & $\begin{array}{l}\text { New business } \\
\text { management } \\
\text { models }\end{array}$ & 16.1 Not to appear & $\begin{array}{l}16.2 \text { Know and apply new } \\
\text { management models that } \\
\text { allow them to work in new } \\
\text { niches and/or cost reduction. }\end{array}$ & $\begin{array}{l}\text { 16.3 Use of new management models } \\
\text { by competitors, generating a } \\
\text { competitive advantage for them. }\end{array}$ \\
\hline
\end{tabular}


The factors considered and listed in Table 12 are inserted in the lines, while the scenarios are the columns. The crossings of rows and columns simply result in the scenarios in which the following steps of the model will be based. It should be added that if it is necessary to test other scenarios beyond the three proposed ones, these can be obtained in the combination of the proposed morphological analysis or the extrapolation of its data. However, as already explained, the construction of many scenarios above 4 can make this analysis too expensive and laborious, and is not applied in the present study. The Scenarios were built with a time horizon of 3 years. This term was defined by the managers because they believe it is a period in which the company can react to some flaw in the plan and considers that the risk involved is acceptable.

\subsection{Step 4 - Creation of Investment Alternatives}

At this step, the company representatives' point out investment possibilities, considering the scenarios encountered. Three alternatives were chosen and it should be clarified that these are investment options for any of the scenarios found, namely:

- $\mathbf{A}_{\mathbf{1}}$ - Creation of new services. In this investment are made offerings of new services, which can or are demanded by the only existing customer or offering new services to new customers. It should be noted that, for this, the company should invest in attracting new customers, in addition to designing other services.

- $\quad \mathbf{A}_{\mathbf{2}}$ - Prospecting new customers. For this investment possibility, it is sought to offer the services already performed for this sole customer to other clients with similar needs. In this way, there will be optimization of the know-how acquired, being necessary only the capture of clients.

- $\mathbf{A}_{3}$ - Search for new niches. Finding new niches requires knowing the niches that XPTO can meet with the services it currently provides and developing them, to offer services to this new demand. It is not ruled out the possibility of some new service or some adjustment in the form of delivery of the current products to meet this objective.

\subsection{Step 5-Application of Multicriteria Method}

In this step, as already explained in the previous chapters, the AHP method was applied for the prioritization of the investment valuation criteria and in each prospective scenario.

Firstly, the criteria for the evaluation of the alternatives $\left(A_{1}, A_{2}\right.$ and $\left.A_{3}\right)$ were selected and defined, namely: Investment (Inv), Return (Ret), Time (Tem) and Market Risk (Ris). It should be clarified that Market Risk is defined as the possibility of occurrence of losses resulting from the fluctuation in the market values of assets and liabilities held by the financial institutions that make up the financial conglomerate J.P. Morgan. This first step can be seen in Table 13.

Scales were then defined for each criterion. Do see Table 14. The reading of the scale indicates that the higher the score obtained, the greater the advantage of one choice over others.

Table 13. Description of the criteria for evaluating opportunities

\begin{tabular}{cc}
\hline Criteria & Criteria descriptions \\
\hline Investment (Inv) & $\begin{array}{c}\text { It is related to the invested capital for the } \\
\text { chosen alternative. }\end{array}$ \\
Return (Ret) & $\begin{array}{c}\text { It is related to the percentage of return on } \\
\text { invested capital. } \\
\text { Time needed to return the invested } \\
\text { capital. }\end{array}$ \\
Time (Tem) & It is related to the market risk \\
Market Risk (Ris) &
\end{tabular}

Table 14. Scale of values for the criteria described at the Board 7 (Source: Authors)

\begin{tabular}{|c|c|c|c|c|}
\hline \multirow[b]{2}{*}{ Investment (value range) } & \multicolumn{2}{|l|}{ Criteria } & \multirow[b]{2}{*}{ Risk } & \multirow{2}{*}{ Scale } \\
\hline & Return on investment (\%) & Time (years) & & \\
\hline Above $\mathrm{R} \$ 200,000.01$ & There is no return & Above 10 years & High risk & 0 \\
\hline $\begin{array}{c}\text { From } R \$ 150,000.01 \text { up to } \\
R \$ 200,000.00\end{array}$ & Up to $5 \%$ per year. & $\begin{array}{l}\text { From } 5 \text { up to } 10 \\
\text { years }\end{array}$ & Moderate risk & 1 \\
\hline $\begin{array}{c}\text { From } \mathrm{R} \$ 100,000.01 \text { up to } \\
\mathrm{R} \$ 150,000.00\end{array}$ & Between 5 up to $10 \%$ per year. & From 3 up to 5 years & Average expected risk & 2 \\
\hline $\begin{array}{l}\text { From } R \$ 50,000.01 \text { up to } \\
\mathrm{R} \$ 100,000.00\end{array}$ & Between 10 up to $20 \%$ per year. & Up to 3 years & Low risk & 3 \\
\hline Up to $R \$ 50,000.00$ & Above $20 \%$ per year & Immediate & No apparent risk & 4 \\
\hline
\end{tabular}


Continuing, it is necessary to know the contribution of each evaluation criterion within each scenario, for this purpose, then, the AHP method was applied. It should be noted that comparisons between criteria (creation of the comparative Matrix of the AHP method) and the judgments resulting from the crossing of the investment alternatives versus the criteria in each scenario were obtained through meetings between two representatives of the XPTO Company and the author of this work. Which consensually reached the results that will be presented in Table 15 the AHP was applied to all Scenarios obtained in Step 3 Construction of Scenarios. For the scenarios of Trend $\left(\mathrm{S}_{1}\right)$, Optimist $\left(\mathrm{S}_{2}\right)$ and Pessimist $\left(\mathrm{S}_{3}\right)$, the comparisons were carried out alongside the suggested criteria, namely: Investment, Return, Time and Risk, according to Saaty's method [54, 55]

Trend Scenario $\left(\mathbf{S}_{1}\right)$ - It was verified that the comparisons for the pair were with the required consistency, this fact could be bought from the tests of Consistency Index $(\mathrm{CI}=0.015)$ and Consistency Ratio (RC $=0.016$ ), Obeying the principles of the method. The parameters resulting from this analysis were: Investment (6.9\%), Return (56.4\%), Time (22.5\%) and Risk (14.3\%). This result could direct the managers to plan investments where, currently, with this Brazilian oil \& gas energy corporation contracts retraction, it is important to prioritize percentage of return and time for resumption of capital, so that the company has flow can remain competitive.

Optimistic Scenario $\left(\mathbf{S}_{2}\right)$ - Also per the method, the comparisons were made alongside the criteria for $\mathrm{S}_{2}$. It was found that $\mathrm{IC}=0.292$ and $\mathrm{RC}=0.325$, resulting in an inconsistent matrix. Through a new analysis and with the aid of the software available at bpmsg.com, changes were made in the relations Time x Return, Risk x Investment, Risk $\mathrm{x}$ Return. These changes resulted in $\mathrm{CI}$ and $\mathrm{RC}=$ 0.000 , by approximation, thus attending to the premises of the method. The final parameterization was composed of $12.5 \%$ for Investment and Risk and; $37.5 \%$ for and Return and Time. In the case of a totally optimistic scenario this solution also translates into a market reality, in which it balances the risk versus return ratio, having its greater importance in the return, since it is favourable in the face of an optimistic scenario.

Pessimistic Scenario $\left(\mathbf{S}_{3}\right)$ - Like the $\mathrm{S}_{1}$ and $\mathrm{S}_{2}$ scenarios, the comparisons were carried out in addition to the known criteria. We found $\mathrm{CI}=0.641$ and $\mathrm{RC}=0.712$, resulting in an inconsistent matrix. Through a new analysis and with the aid of the software available at bpmsg.com, changes were made in the relations Time and Return; Risk and Time; and Risk and Return. These changes resulted in $\mathrm{CI}=$ 0.038 and $\mathrm{RC}=0.042$, thus meeting the assumptions of the method. The final parameterization was composed of $10.3 \%$ - Investment; $26.4 \%$ - Return; 35.7\% - Time and $27.5 \%$ - Risk.

In analysing the results obtained for the pessimistic scenario, managers considered the greater risk involved in the investments and their need for rapid return. They understood the need for the company to reinvent itself abruptly in the case of the concretization of this scenario. These calculations are seen in Table 15 below.

Table 15. Prioritization of the criteria for $\mathrm{S}_{1}, \mathrm{~S}_{2}$ and $\mathrm{S}_{3}$ - Application of the AHP method

\begin{tabular}{|c|c|c|c|c|c|c|c|c|c|c|c|c|c|}
\hline \multicolumn{14}{|c|}{ Trend Scenario $\left(\mathrm{S}_{1}\right)$} \\
\hline \multicolumn{6}{|c|}{ Comparative matrix } & \multicolumn{8}{|c|}{ Method of Average of Normalized Values } \\
\hline \multirow{5}{*}{$\begin{array}{c}\text { criteria } \\
\text { Inv. } \\
\text { Ret. } \\
\text { Tem. } \\
\text { Ris }\end{array}$} & Inv. & Ret. & Tem. & Ris & Eigenvector & \multicolumn{5}{|c|}{ Standard Matrix } & PML & \multirow{2}{*}{$\begin{array}{c}\begin{array}{c}\text { Val } \\
\text { Eigen }\end{array} \\
\mathrm{n}\end{array}$} & \multirow{2}{*}{$\begin{array}{l}4.044 \\
4.000\end{array}$} \\
\hline & 1 & $1 / 5$ & $1 / 5$ & $1 / 3$ & 0.3398 & Inv & 0.071 & 0.115 & 0.043 & 0.045 & 0.069 & & \\
\hline & 5 & 1 & 3 & 5 & 2.9428 & Ret & 0.357 & 0.577 & 0.638 & 0.682 & 0.564 & IR & 0.900 \\
\hline & 5 & $1 / 3$ & 1 & 1 & 1.1362 & Tem & 0.357 & 0.192 & 0.213 & 0.136 & 0.225 & IC & 0.015 \\
\hline & 3 & $1 / 5$ & $1 / 2$ & 1 & 0.7401 & Ris & 0.214 & 0.115 & 0.106 & 0.136 & 0.143 & $\mathrm{RC}$ & 0.016 \\
\hline \multirow[t]{2}{*}{ Sum } & 14.00 & 1.73 & 4.70 & 7.33 & 5.1589 & & & & & & & & \\
\hline & Compar & ive $\mathrm{m}$ & trix & & & \multicolumn{8}{|c|}{ Method of Average of Normalized Values } \\
\hline criteria & Inv & Ret & Tem & Ris & Eigenvector & \multicolumn{5}{|c|}{ Standard Matrix } & PML & $\begin{array}{c}\text { Val } \\
\text { Eigen }\end{array}$ & 4.059 \\
\hline Inv & 1 & $1 / 5$ & $1 / 3$ & $1 / 3$ & 0.3861 & Inv & 0.083 & 0.107 & 0.063 & 0.063 & 0.079 & $\mathrm{n}$ & 4.000 \\
\hline Ret & 5 & 1 & 3 & 3 & 2.5900 & Ret & 0.417 & 0.536 & 0.563 & 0.563 & 0.519 & IR & 0.900 \\
\hline Tem & 3 & $1 / 3$ & 1 & 1 & 1.0000 & Tem & 0.250 & 0.179 & 0.188 & 0.188 & 0.201 & IC & 0.020 \\
\hline Ris & 3 & $1 / 3$ & 1 & 1 & 1.0000 & Ris & 0.250 & 0.179 & 0.188 & 0.188 & 0.201 & $\mathrm{RC}$ & 0.022 \\
\hline Sum & 12.00 & 1.87 & 5.33 & 5.33 & 4.9761 & & & & & & & & \\
\hline \multicolumn{14}{|c|}{ comparisons $=6$} \\
\hline
\end{tabular}




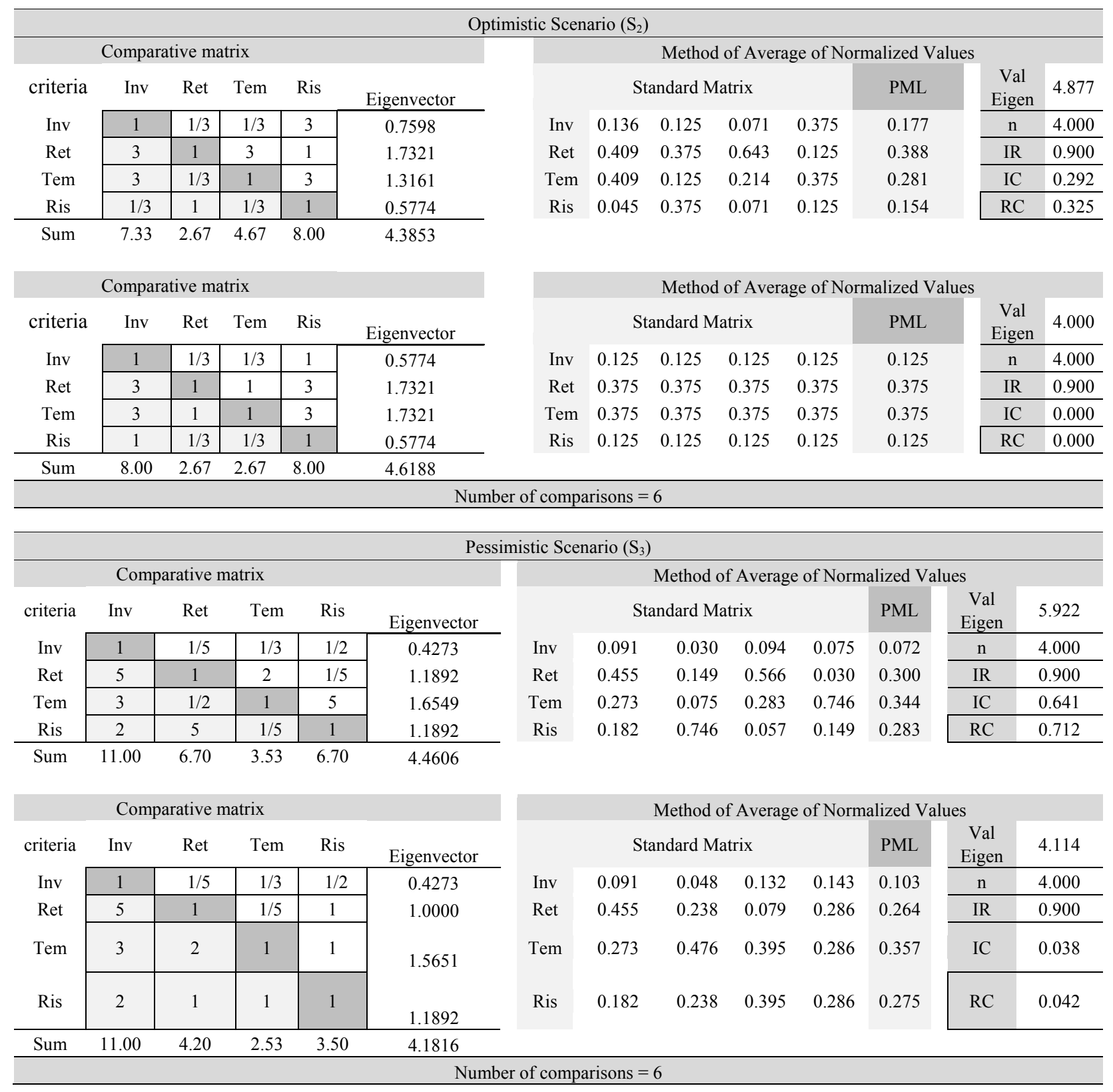

\subsection{Step 6 - Definition of the Investment Alternative}

At this stage of the definition of the best investment to be carried out, it is up to the managers to evaluate the possible best solutions to be considered in Strategic Planning, which has a time horizon of 3 years, so that the objective of managerial support will be achieved by the decision of the model here proposed. As explained in the description of the Model, the decision problems can be discrete or continuous. In this stage of the application, the alternatives have already been proposed in Step 4, and are therefore finite or discrete.

\section{Discussion}

It is possible to verify in Table 16 that, in case of the
Trend Scenario Trend and a Pessimistic Scenario (described in tables 12), the best investment alternative would be the search for new customers $\left(\mathrm{A}_{2}\right)$ and the maintenance of the services already offered. In the discussion of these results with the managers of the studied company, the following points were addressed: (i) in the case of the market trend that the services volume sales decreases or even the occurrence of events that make the future scenario pessimistic, investing in the search for new clients is adequate, since not all sectors of the economy are affected by times of recession; (ii) as a consequence of the search for new clients, it is natural that there is a need to adapt the services currently provided. In the case of the occurrence of an Optimistic Scenario (Tables 12 and 16), the creation and offer of new services $\left(\mathrm{A}_{1}\right)$ would be the best option for investment. The managers emphasized that 
from the creation of new products, besides the possibility of offering more fully their current single customer, attending to other markets would only be a consequence.

Table 16. Indication of the most advantageous alternative fo Trend, Optimistic and Pessimistic Scenarios

\begin{tabular}{|c|c|c|c|c|c|}
\cline { 2 - 5 } \multicolumn{1}{c|}{} & \multicolumn{4}{c|}{ Trend Scenario $\left(\mathrm{S}_{1}\right)$} & \multicolumn{1}{c}{} \\
\hline \multirow{2}{*}{ Alt./criteria } & $\begin{array}{c}\text { Inv } \\
6.9 \%\end{array}$ & $\begin{array}{c}\text { Ret } \\
56.4 \%\end{array}$ & $\begin{array}{c}\text { Tem } \\
22.5 \%\end{array}$ & $\begin{array}{c}\text { Ris } \\
14.3 \%\end{array}$ & \multirow{2}{*}{ Summary } \\
\hline $\mathrm{A}_{1}$ & 3 & 2 & 3 & 1 & 2.15 \\
\hline $\mathrm{A}_{2}$ & 3 & 3 & 1 & 3 & 2.55 \\
\hline $\mathrm{A}_{3}$ & 1 & 3 & 1 & 2 & 2.27 \\
\hline
\end{tabular}

\begin{tabular}{|c|ccc|c|c|}
\cline { 2 - 5 } \multicolumn{1}{c|}{} & \multicolumn{4}{c|}{ Optimistic Scenario $\left(\mathrm{S}_{2}\right)$} & \multicolumn{1}{c}{} \\
\hline \multirow{2}{*}{ Alt./criteria } & $\begin{array}{c}\text { Inv } \\
12.5 \%\end{array}$ & $\begin{array}{c}\text { Ret } \\
\text { In }\end{array}$ & $\begin{array}{c}\text { Tem } \\
\text { Tem }\end{array}$ & $\begin{array}{c}\text { Ris } \\
\text { R. }\end{array}$ & \multirow{2}{*}{ Summary } \\
\hline $\mathrm{A}_{1}$ & 4 & 3 & 4 & 4 & 3.63 \\
\hline $\mathrm{A}_{2}$ & 4 & 3 & 4 & 3 & 3.50 \\
\hline $\mathrm{A}_{3}$ & 3 & 3 & 3 & 4 & 3.13 \\
\hline
\end{tabular}

\begin{tabular}{|c|c|c|c|c|c|}
\hline \multirow{3}{*}{ Alt./criteria } & \multicolumn{4}{|c|}{ Pessimistic Scenario $\left(\mathrm{S}_{3}\right)$} & \multirow[b]{3}{*}{ Summary } \\
\hline & Inv & Ret & Tem & Ris & \\
\hline & $10.3 \%$ & $26.4 \%$ & $35.7 \%$ & $27.5 \%$ & \\
\hline $\mathrm{A}_{1}$ & 1 & 2 & 2 & 1 & 1.62 \\
\hline $\mathrm{A}_{2}$ & 1 & 1 & 3 & 2 & 1.99 \\
\hline $\mathrm{A}_{3}$ & 0 & 1 & 2 & 2 & 1.53 \\
\hline
\end{tabular}

In the case of the occurrence of an Optimistic Scenario, the creation and offer of new services $\left(A_{1}\right)$ would be the best option for investment. Exploring the Scenarios possibilities, in isolation, corroborated the possibility of using $\mathrm{S}_{4}$ (Integrated Scenarios - Table 17) in the planning of the company. It is noticed that the solutions envisaged by the managers converge to create new products and from these to seek new markets, or to look for new markets and from the adaptation of the services currently provided, to create new services. This validation brings flexibility to the company's positioning from future scenarios.

It is worth mentioning that it is impossible to create a generic structuring procedure whose application can guarantee the unity and validity of the designed model, and how the objective of this work is the proposition of a model that is a support tool for planning, considering scenarios in isolation tends to make the theoretical model. For this reason, it was proposed to use the Integrated Scenarios $\left(\mathrm{S}_{4}\right)$, with the intention of having as base a scenario generated from the contribution of all the others, idealized in an isolated way, resulting in a scenario closer to reality.

Table 17 shows the contribution of each alternative pair versus criterion for each scenario; where the summary of the product of the absolute values chosen for each alternative by the percentage prioritized in each scenario. For this Integrated Scenario, what can be noticed is the highest score for the new customer search alternative $\left(\mathrm{A}_{2}\right)$

It should be noted that the decision of the managers for the investments with the highest score in each scenario, considered the most daring profile of these. For this reason, the traditional max-max analysis method was used, where the best of each alternative is selected in each state of the future nature, and subsequently the best of the maxima was chosen.

During its application in an engineering services company, it was possible to observe benefits expressed by the managers and key stakeholders. It should also be emphasized that the first stage should be sufficiently explored so that the context and environment in which the company to be studied can be known, and it has been clearly demonstrated that this stage must be exhausted in possibilities.

Limitations were also identified regarding the evaluation of the results of the model, because of its application in a single company belonging to a single niche. If this model were applied in other companies, it could be validated with greater precision; already to measure if it is adequate for the reduction of the risks when applying the model, would require time, in the specific case of the present work, 3 years would already be sufficient, since this was the time horizon predicted.

Table 17. Indication of the most advantageous alternative for Integrated Scenarios $\left(\mathrm{S}_{4}\right)$ (Source: Authors)

\begin{tabular}{|c|c|c|c|c|c|c|c|c|c|c|c|c|c|}
\hline \multirow{3}{*}{$\begin{array}{c}\text { Alt./ } \\
\text { scenarios } \\
\text { - criteria }\end{array}$} & \multicolumn{13}{|c|}{ Integrated Scenarios $\left(\mathrm{S}_{4}\right)$} \\
\hline & $\mathrm{S}_{1}, \mathrm{Inv}$ & $\mathrm{S}_{1}$, Ret & $\mathrm{S}_{1}$, Tem & $\mathrm{S}_{1}$, Ris & $\mathrm{S}_{2}$, Inv & $\mathrm{S}_{2}$, Ret & $\mathrm{S}_{2}$, Tem & $\mathrm{S}_{2}$, Ris & $\mathrm{S}_{3}$, Inv & $\mathrm{S}_{3}$, Ret & $\mathrm{S}_{3}$, Tem & $\mathrm{S}_{3}$, Ris & \multirow{2}{*}{ Summary } \\
\hline & $2.3 \%$ & $18.8 \%$ & $7.5 \%$ & $4.8 \%$ & $4.2 \%$ & $12.5 \%$ & $12.5 \%$ & $4.2 \%$ & $3.4 \%$ & $8.8 \%$ & $11.9 \%$ & $9.2 \%$ & \\
\hline $\mathrm{A}_{1}$ & 3 & 2 & 3 & 1 & 4 & 3 & 4 & 4 & 1 & 2 & 2 & 1 & 2.47 \\
\hline $\mathrm{A}_{2}$ & 3 & 3 & 1 & 3 & 4 & 3 & 4 & 3 & 1 & 1 & 3 & 2 & 2.68 \\
\hline $\mathrm{A}_{3}$ & 1 & 3 & 1 & 2 & 3 & 3 & 3 & 4 & 0 & 1 & 2 & 2 & 2.31 \\
\hline
\end{tabular}




\section{Conclusions}

It was possible to conclude that the general objective was reached, since the proposal of integration between scenarios and multicriteria decision analysis techniques was applied in a company, more specifically using the AHP technique; to support the development of strategic planning.

The intention was to instrumentalist an activity essential for the survival of companies, Strategic Planning, since they have empirical characteristics, and depends on the experience and/or interest of the main stakeholders. With this integration of techniques, it was possible to treat partiality and subjectivity, since it relies on scientific methods to do so.

It is worth highlighting the specific objectives proposed in this paper:

a. Develop the model as a tool to aid strategic planning: the objective of developing a tool model to aid strategic planning was achieved because managers could have new perceptions and insights related to their market, their company and their position before the market and its form of management.

b. Propose the combination of a MCDA technique with the planning of future scenarios: the AHP technique was chosen to be used in this model, given specific characteristics of this technique that meet the objective of the model and the interface with the users, such as Such as allowing a large amount of judgment on problems with many criteria and alternatives, allows the use of qualitative and quantitative data, it is not necessary to treat the data before its use, it allows group decision, among others.

c. Apply the tool to an engineering services company, located in the state of Rio de Janeiro: as planned at the beginning of this research. There was no restriction of information or difficulties for meetings; on the contrary, there was interest on the part of the company for the result. Still in relation to its application, it can be perceived that the scale to be developed for the criteria used should be well defined and as a suggestion of improvement, a way of standardization can be studied. The need for a multidisciplinary team in the actual stages was evident, so that the possibilities in front of different points of view of the business studied could be exhausted.

Gomes et al [38] suggest that cultures and political analyses and / or economic and other, to build scenarios power shall be used from other combinations, which creates an important line of research. All those variables are present on Tables 11 and 12; these variables are main predictors for scenario planning in engineering sector

Therefore, the authors intended with this paper to propose a different way of integrating scenarios and multicriteria analysis techniques into the decision and to direct it to help strategically plan because we believe in the contribution in two aspects, the first one is that this possibility of integration between scenarios with decision aid techniques resulting in instrumentation for strategic planning can occur in a variety of ways and the second aspect is to contribute to such an important business activity for planning.

\section{REFERENCES}

[1] Ab Kadir, M. Z. A., Rafeeu, Y. \& Adam, N. M. (2010). Prospective Scenarios for the Full Solar Energy Development in Malaysia. Renewable and Sustainable Energy Reviews, 14(9), 3023-3031.

[2] Ackoff, R. L. (1970). A Concept of Corporate Planning. John Wiley \& Sons: New York.

[3] Amer, M.; Daim, T.U.; \& Jetter, A. (2013). A Review of Scenario Planning. Futures, 46, 23-40.

[4] Amit, R.; Schoemaker, P. (1993). Strategic Assets and Organizational Rent. Strategic Management Journal, Chichester, 14(1), 33-46.

[5] Archer, N.; \& Ghasemzadeh, F. (1999). An Integrated Framework for Project Portfolio Selection. International Journal of Project Management, 17 (4), 207-216.

[6] Atherton, A. (2005). A Future for Small Business? Prospective Scenarios for the Development of the Economy Based on Current Policy Thinking and Counterfactual Reasoning. Futures, 37(8), 777-794.

[7] Bezold, C. (2010). Aspirational Futures. Journal of Futures Studies, 13, 81-90.

[8] Bishop, P.; Hines, A.; \& Collins, T. (2007). The Current State of Scenario Development: An Overview Of Techniques. Foresight 9, 5-25.

[9] Borjeson, L.; Ho Jer, M.; Dreborg, H. K.; Ekvall, T.; \& Finnveden, G. (2006). Scenario Types and Techniques: Towards A User's Guide. Futures, 38, 723-739.

[10] Bornia, A. C.; \& Wernke, R. (2001). A Contabilidade Gerencial E Os Métodos Multicriteriais. Revista Contabilidade \& Finanças, 14(25), 60-71.

[11] Brabandere, De L.; Iny, A. (2010). Scenarios and Creativity: Thinking in New Boxes. Technological Forecasting and Social Change, 77, 1506-1512.

[12] Brafield, R.; Wright, G.; Burt, G.; Cairns, K.; \& Van Der Heijen. (2005). The Origins and Evolution Of Scenario Techniques In Long Range Business Planning. Futures 37, 795-812.

[13] Bramley, G.; \& Watkins, D. (2016). Housebuilding, Demographic Change and Affordability As Outcomes Of Local Planning Decisions: Exploring Interactions Using A Sub-Regional Model Of Housing Markets In England. Progress in Planning, 104, 1-35. 
[14] Bunn, D. W.; \& Salo, A. A. (1993). Forecasting with Scenarios, European Journal of Operational Research, 68, 291-303.

[15] Burt, G.; \& Van Der Heijen, K. (2003). First Steps: Towards Purposeful Activities in Scenario Thinking and Future Studies. Futures 35, 1011-1026.

[16] Chermack, T.J.; Lynham, S.A.; \& Van Der Merwe, L. (2006). Exploring the Relationship between Scenario Planning and Perceptions of Learning Organization Characteristics. Futures, 38, 767-777.

[17] Chermack, T.J.; Lynham, S.A.; Ruona, W.E.A. (2001). A Review of Scenario Planning Literature. Futures Research Quarterly, 17, 7-31.

[18] Cooper, R. G., Edgett, S. J., \& Kleinschmidt, E. J. Portfolio Management for New Product Development: Results of An Industry Practices Study. R\&D Management, 31 (4) (2001).

[19] Coyle, R.G., \& Mcglone, G.R. (1995). Projecting Scenarios for South-East Asia and the South-West Pacific. Futures, 27, 65-79.

[20] Dane, E., \& Pratt, M. G. (2007). Exploring Intuitation and Its Role in Managerial Decision Making, Academy of Management Review, 1(32), 33-54.

[21] Daychouw, M. (2010) Ferramentas E Técnicas De Gerenciamento. 3. Ed. Rio de Janeiro: Brasport, 2010.

[22] Derbyshire, J, \& Wright, G. (2017) Augmenting the intuitive logics scenario planning method for a more comprehensive analysis of causation. International Journal of Forecasting.

[23] Dong, Q., \& Cooper, O. (2016). A Peer-To-Peer Dynamic Adaptive Consensus Reaching Model For The Group AHP Decision Making. European Journal of Operational Research, 250, 521-530.

[24] Dudley, H. A. F., Brown, S. P., Thomson, J. N., \& Eckersley, J. R. (1989). Prospective Scenarios: A Method of Evaluating New Decision Tools. World Journal of Surgery, 13(3), 277-280.

[25] Durance, P. (2010). Reciprocal Influences In Future Thinking Between Europe and the USA. Technological Forecasting and Social Change, 77, 1469-1475.

[26] Durance, P., \& Godet, M. (2010). Scenario Building: Uses and Abuses. Technological Forecasting and Social Change, 77, 1488-1492.

[27] Ekera, S., Daalena, E. V., \& Thissena. W. (2017). Incorporating Stakeholder Perspectives into Model-Based Scenarios: Exploring the Futures of the Dutch Gas Sector. Futures, Volume 93, Pages 27-43

[28] European Commission (2002) Practical Guide to Regional Foresight in Portugal.

[29] Fabre, J., Ruelland, D., Dezetter, A. \& Grouillet, B. (2015). Simulating Past Changes in the Balance between Water Demand and Availability and Assessing Their Main Drivers at the River Basin Scale. Hydrology and Earth System Sciences.

[30] Fahey, L. E Randall, R. (1998). Learning from the Future, New York, John Wiley \& Sons, 57-80.
[31] Ferretti, V. (2016). From Stakeholders Analysis to Cognitive Mapping and Multi-Attribute Value Theory: An Integrated Approach for Policy Support. European Journal of Operational Reserch, 253, 524-541.

[32] Fouquet, M., Levasseur, A., Margni, M., Lebert, A., Lasvaux, S., Souyri, B. \& Woloszyn, M. (2015). Methodological Challenges and Developments in Lca of Low Energy Buildings: Application to Biogenic Carbon and Global Warming Assessment. Building and Environment.

[33] Ghemawat, P. (2002). Competition and Business Strategy in Perspective. Business History Review, 76(1), 37-74.

[34] Godet, M. (1996). Creating the Future: The Use and Misuse Of Scenarios", Long Range Planning, 29(2), Pp.164-177.

[35] Godet, M. (2000). The Art of Scenarios and Strategic Planning: Tools and Pitfalls. Technological Forecasting and Social Change, 65, 3-22.

[36] Gomes, C. F. S.; Gomes, L. F. A. M.; \& Francisco José Coelho Maranhão. Decision Analysis for the Exploration of Gas Reserves: Merging Todim and Thor. Pesquisa Operacional (Impresso), V. 30, P. 601-617, 2010.

[37] Gomes, C. F.S. (2005). Using MCDA Methods Thor in an Application for Outranking the Ballast Water Management Options. Pesquisa Operacional, 25(1), 11-28.

[38] Gomes, C.F.S. Costa, H. G., \& Barros, A. P. (2017) "Sensibility Analysis of MCDA Using Prospective in Brazilian Energy Sector". Journal of Modelling In Management. Article In Press,

Https://Doi.Org/10.1108/Jm2-01-2016-0005

[39] Gordon, T. J. (1994), Cross Impact Method, United Nations University Millennium Project, 1.

[40] Grandzol, J.R. (2005). Improving the Faculty Selection Process in Higher Education: A Case for the Analytic Hierarchy Process. Bloomsburg University of Pennsylvania. Ir Applications, 6.

[41] Grant, R. M. (2010). Contemporary Strategy Analysis, John Wiley \& Sons, $7^{\text {a }}$ Ed.

[42] Hax, A. C.; \& Majluf, N. S., The Strategy Concept and Process - A Pragmatic Approach, New Jersey, Prentice Hall, 1996.

[43] Ho, W. (2008). Integrated Analytic Hierarchy Process and Its Applications - A Literature Review. European Journal of Operational Research, 86(1), 211-228.

[44] Ho, W., Xu, X., \& Dye, P.K. (2010). Multi-Criteria Decision-Making Approaches for Supplier Evaluation and Selection: A Literature Review. European Journal of Operational Research, 202, 16-24. Doi:10.1016/J.Ejor.2009.05.009

[45] Jenkins, L. (1997). Selecting a Variety of Futures for Scenario Development. Technological Forecasting and Social Change 55, 15-20.

[46] Joseph, C.F. (2000). Scenario Planning. Technological Forecasting and Social Change 65, 115-123.

[47] Kadziński, M., \& Tervonen, T. (2013). Robust Multi-Criteria Ranking with Additive Value Models and Holistic Pair-Wise Preference Statements. European 
Journal of Operational Research, 228(1), 169-180.

[48] Kotler, P. (2016). Pest Analysis. Available At: < Http://Philipkotler2013.Blogspot.Com.Br/2011/11/Pest-An alysis.Htm L >. Accessed: August 11th, 2016.

[49] Lange, J. M. (2012). Education in Sustainable Development: How Can Science Education Contribute to The Vulnerability Perception? Research in Science Education, 42(1), 109-127.

[50] Melo, R. M. M., Medeiros, D. D., \& Almeida, A. T. (2015). Multicriteria Model for Ranking of Improvement Approaches in Construction Companies Based on the Promethée Ii Method. Production, 25(1), 69-78. Doi: Http://Dx.Doi.Org/10.1590/S0103-65132013005000069

[51] Millan, J. J. G.; Diaz, M. T. R.; \& Moreno-Corredor, L. A. (2014). Caracterización De La Gestión Estratégica De Las Grandes Empresas Del Valle De Sugamuxi Del Departamento De Boyacá, Colombia. Entramado,10 (1), 106-124.

[52] Mora-Riapira, E. H.; Colinab, M. A. V.; \& Molina, Z. A. M. (2014). Planificación Estratégica Y Niveles De Competitividad De Las Mipymes Del Sector Comercio En Bogotá. Estudios Gerenciales 31, 79-87. Http://Dx.Doi.Org/10.1016/J.Estger.2014.08.001

[53] Porter, M.; Ketels, C.; \& Delgado, M. (2007). The Microeconomic Foundations of Prosperity: Findings from the Microeconomic Competitiveness Index. Wef - World Economic Forum. The Global Competitiveness Report 2007-2008. New York: Palgrave Macmillan, 2007. P. 51-81.

[54] Saaty, T. L., \& Vargas, L. G. (2013). The Logic of Priorities: Applications of the Analytic Hierarchy Process in Business, Energy, Health \& Transportation. Ed Rws, Pittsburgh.

[55] Saaty, T. L., \& Ergo, D. (2015). When Is a Decision-Making Method Trustworthy? Criteria for Evaluating Multi-Criteria Decision-Making Methods. International Journal of Information Technology \& Decision Making, 14(6), 1171-1187.

[56] Saebi, T.; Lien, L.; Foss, N. J. (2016). What Drives Business Model Adaptation? The Impact of Opportunities, Threats and Strategic Orientation. Long Range Planning.

[57] Sarpong, D.; \& Maclean, M. (2011). Scenario Thinking: A Practice-Based Approach for the Identification of Opportunities for Innovation, Futures 43, 1154-1163.

[58] Schoemaker, P.J.H. (1993). Multiple Scenario Development: Its Conceptual and Behavioral Foundation, Strategic Management Journal 14, 193-213.

[59] Schoemaker, P.J.H. (1995). Scenario Planning: A Tool for Strategic Thinking. Sloan Management Review, 36 (Winter). 25-40.

[60] Schoemaker, P.J.H.; \& Van Der Heijden, C.A.J.M., (1992), Integrating Scenarios into Strategic Planning at Royal Dutch/Shell, Strategy \& Leadership 20, 41-46.

[61] Schwabs, P.; Cerutti, F.; \& Reibnitz, U.H. (2003), Foresight - Using Scenarios To Shape The Future Of Agricultural Research. Foresight 5, 55-61.
[62] Schwartz, P. (1996). The Art of the Long View: Planning for the Future in an Uncertain World, Currency Doubleday, New York.

[63] Schwartz, P. (1998). The Art of the Long View. John Wiley \& Sons: New York.

[64] Silva, A. T. B.; Spers, R. G.; \& Wright, J. T. C. (2012). The Development of Scenarios In Strategic Management Of Organizations: A Literature Study. Revista De Ciências Da Administração, V. 14, N. 32, P. 21-34.

[65] Souza, I. D. Da S.; \& Takahashi, V. P. (2012). A Visão De Futuro Por Meio De Cenários Prospectivos: Uma Ferramenta Para an Antecipação Da Inovação Disruptiva. Future Studies Reserch Journal, 102-132.

[66] Subramanian, N., \& Ramanathan, R.A. (2012). Review of Applications of Analytic Hierarchy Process in Operations Management. International Journal of Production Economics, 138 (2), 215-241.

[67] Tsoukiàs, A.; Montibeller, T.; Lucertini, G.; \& Belton, V. (2013). Policy Analytics: An Agenda for Research and Practice. Euro Journal of Decision Processes, 1, 115-134

[68] Varum, C.A.; \& Melo, C. (2010), Directions in Scenario Planning Literature. A Review of the Past Decades. Futures, 42,355-369.

[69] Vecchiato, R.; \& Roveda, C. (2010), Strategic Foresight in Corporate Organizations: Handling the Effect and Response Uncertainty of Technology and Social Drivers of Change. Technological Forecasting and Social Change, 77, 15271539.

[70] Vervoorta, B, J. M., Bendorc, R., Kelliherd, A., Strike, O., \& Helfgotta, A. E. R. (2015). Scenarios and the Art of Worldmaking. Futures, 74, 62-70.

Http://Dx.Doi.Org/10.1016/J.Futures.2015.08.009

[71] Vieira, J.A.M; Gomes, C.F.S.; \& Braga, I.E. (2017). Development of a Scenario Prospecting Model with the Use of Multicriteria Decision Aiding: Importance of Environmental Variables. Brazilian Journal of Operations and Production Management, V. 14, P. 210-217.

[72] Wack, Pierre. (1985). "Scenarios: Uncharted Waters Ahead", Harvard Business Review. September-October.

[73] Wang, X. P.; Zhang, J.; \& Yang, T. (2014). Hybrid Swot Approach for Strategic Planning and Formulation in China Worldwide Express Mail Service. Journal of Applied Research and Technology, Vol. 12.

[74] Xi, X., \& Qin, Q. (2013). Product Quality Evaluation System Based on AHP Fuzzy Comprehensive Evaluation. Journal of Industrial Engineering and Management, 6(1), 356-366. Http://Dx.Doi.Org/10.3926/Jiem.685

[75] Yichuan, Z.; \& Lei, F. (2013). Development Assessment of Leisure Agriculture in Henan Province of China Based on Swot-Ahp Method. Journal of Industrial Engineering and Management, Vol. 6, No. 2, Pp. 642-653, 2013.

[76] Zwicky, F. (1969), Discovery, Invention, Research Through the Morphological Approach, Toronto: The Macmillan Company. 